\title{
O ETANOL E A REPRODUÇÃO DO CAPITAL EM CRISE
}

\section{ETHANOL AND CAPITAL IN CRISIS REPRODUCTION}

\section{EL ETANOL Y LA REPRODUCCIÓN DEL CAPITAL EN CRISIS.}

Fábio T. Pitta

Doutorando do Programa de Pós-Graduação em Geografia Humana Faculdade de Filosofia, Letra e Ciências Humanas

Universidade de São Paulo pitta.fabio@gmail.com

Maria Luisa Mendonça Doutoranda do Programa de Pós-Graduação em Geografia Humana Faculdade de Filosofia, Letra e Ciências Humana Universidade de São Paulo. mmendonca@usp.br

Resumo: $\mathrm{O}$ artigo analisa as tendências mais recentes no setor canavieiro e avalia o crescente processo de formação de monopólios, principalmente com participação de empresas multinacionais. O estudo observa que a maior concentração de capitais é acompanhada pelo aumento da expansão territorial do monocultivo da cana, principalmente em áreas com acesso a infraestrutura, como a região Sudeste, e em regiões com vastas bacias hidrográficas, como o Cerrado. Este processo de crescimento contraditório tem como determinação a crise econômica mundial, no momento de preponderância de capitais financeiros. Neste contexto, o estudo mostra a constante dependência da indústria da cana de créditos estatais e subsídios, além da permanência da superexploração do trabalho.

Palavras-chave: etanol; modernização; agroindústria canavieira; superexploração do trabalho; crise.

\begin{abstract}
This essay analyzes the recent tendencies in the sugarcane sector, and evaluates the increasing process of monopolization, particularly with the participation of multinational corporations. The study observes that the larger concentration of capital coincides with the increasing territorial expansion of sugarcane monocropping, especially in areas with access to infrastructure, in the Southeast region, and in regions with vast water resources in the Cerrado. This process of contradictory "growth" is determined by the international economic crisis, in a moment of the predominance of financial capital. In this context, the study shows a constant dependency of the sugarcane industry on subsidies and state credit, in addition to the permanence of labor exploitation.
\end{abstract}

Keywords: ethanol; modernization; sugar cane agribusiness; labor exploitation; crisis. 
Resumen: El artículo analiza las tendencias más recientes en el sector azucarero y evalúa el proceso, cada vez más intenso, de formación de monopolios, principalmente con participación de empresas transnacionales. El estudio permite observar que la mayor concentración de capitales está siendo acompañada por un aumento de la expansión territorial del monocultivo de caña de azúcar, en especial en áreas con acceso a infraestructura, como es el caso de la región Sureste, y en regiones con grandes cuencas hidrográficas, como en el caso del Cerrado. Este proceso de crecimiento contradictorio está determinado por la crisis económica mundial, en un momento en que predominan los capitales financieros. En este contexto, el estudio demuestra la constante dependencia de la industria cañera de créditos estatales y subsidios, así como la permanencia de prácticas como la explotación de la fuerza de trabajo.

Palabras clave: etanol; modernización; agroindustria de la caña de azúcar; sobreexplotación de la fuerza de trabajo; crisis.

\section{O etanol e a reprodução do capital em crise}

\section{Introdução}

A agroindústria canavieira apresentou crescimento de sua produção ao longo dos dois mandatos do presidente Luiz Inácio "Lula" da Silva (2003-2010) - com exceção do final de seu governo, após a crise de 2008. Essa expansão ocorreu em consequência de políticas governamentais para incentivar a produção de etanol, com a expectativa de aumento da demanda do produto no mercado externo. Um marco para o incentivo dessa política foi a visita do presidente dos Estados Unidos George W. Bush ao Brasil, em 2007. No encontro, Lula afirmou que "Essa parceria pode significar um novo momento da indústria automobilística no mundo, dos combustíveis e um novo momento para a humanidade" (UOL, 2007). O principal resultado do encontro entre os dois presidentes foi a assinatura de um memorando de intenções para estimular a produção de etanol em diversos países. Segundo o subsecretário de Assuntos Políticos do Departamento de Estado dos EUA, Nicholas Burns, essa medida significaria uma "revolução mundial" (Folha de São Paulo, 2007a). Dias depois, Lula classificaria os usineiros como "heróis nacionais e mundiais" (Folha de São Paulo, 2007b).

As principais justificativas apresentadas para a elevação da demanda por produção de cana e seus produtos foram "excelentes perspectivas do comércio interno e internacional, tanto para o açúcar, quanto para o álcool; a elevação dos preços 
internacionais do petróleo; o crescimento da demanda interna de álcool hidratado, devido ao sucesso dos automóveis flex fuel, movidos tanto a álcool, quanto a gasolina; o efeito do protocolo de Kyoto, que ao impor a redução, por parte dos países signatários, das emissões de $\mathrm{CO}_{2}$, tem provocado o crescimento da demanda externa por álcool anidro; a incapacidade dos EUA, maior produtor mundial de álcool de milho, de atender ao crescimento de sua demanda interna por álcool e, tampouco, da demanda externa, o que deixa este mercado aberto ao álcool do Brasil; além dos baixos custos de produção do açúcar e do álcool no Brasil”" (GONÇALVES, 2009: 2).

A partir deste excerto, é possível explicitar por quais perspectivas passam os debates acadêmicos e o discurso da mídia acerca dos incentivos estatais, principalmente provenientes do BNDES (Banco Nacional de Desenvolvimento Econômico e Social) para a agroindústria canavieira. Desejamos com isso, demonstrar que uma leitura crítica à naturalização e positivação do crescimento econômico, ou ao trabalho se entendido como mediação para realização "identitária” (ADORNO, 1966) entre o planejamento humano e seu resultado sobre os objetos da natureza, tem iminente relevância no “momento fictício de reprodução do capital” (KURZ, 1995).

Primeiramente, se faz necessário problematizar a própria concepção causal acerca de que o que possibilitou o novo ciclo de consumo do etanol tenha sido a invenção dos motores flex fuel, que permitem que o usuário escolha abastecer com gasolina ou etanol, conforme o que for economicamente mais viável. Vale dizer que, dado o menor rendimento do segundo frente ao primeiro combustível, só fica mais vantajoso consumir o etanol quando ele for menos de $70 \%$ o preço da gasolina (OGATA, 2009). Localizar em uma descoberta científica a causa do crescimento econômico positivado é não atentar para os processos históricos que ocorrem "às costas dos sujeitos" (MARX, 1983, L.I, T.1, Cap. 1). Se é a necessidade de vencer a concorrência entre capitalistas para realização das mercadorias que leva às inovações científicas - apesar da aparência de liberdade na formulação das necessidades humanas a serem satisfeitas pelas mercadorias - devemos fundamentar a crítica ao modo de produção capitalista nos processos históricos contraditórios aos quais estamos sujeitados. 
José Baccarin (2006), ao historicizar a agroindústria canavieira na década de 1990 e no início do século XXI, nos fornece importantes informações para avaliarmos como foi possível ao setor parecer solvente, após o álcool combustível ter sido pouco relevante economicamente em conseqüência da crise do Proálcool ${ }^{1}$, e, ainda, poder voltar a se endividar. Baccarin (2006) demonstra que, após a "desregulamentação", a partir da extinção do IAA (Instituto do Açúcar e do Álcool)², ocorreu um processo que garantia a competitividade do etanol perante a gasolina, o que preparou o mercado de consumo de veículos flex fuel:

“A ação governamental não foi unilateral no sentido da desregulamentação plena. Em direção contrária, fruto da ação de empresários e de seus representantes políticos, foram implantadas medidas destinadas à maior regulamentação. Assim, em 1993, a Lei $8.723 / 93$ tornava obrigatória a mistura de $22 \%$ de álcool anidro à gasolina. Com a lei 10.203/2001, esse percentual passou a variar entre $20 \%$ e 24\%. Já a aprovação da Lei 10.336/2001, instituindo a Contribuição de Intervenção no Domínio Econômico (CIDE) e da Lei 10.453/2002, conhecida com Lei do Álcool, teve o efeito de sobretaxar o consumo da gasolina em benefício do álcool e de criar uma fonte específica de recursos públicos para financiamento da produção e da estocagem do álcool combustível e da sua matériaprima, a cana-de-açúcar, entre outras atividades" (BACCARIN, 2006: 2).

\footnotetext{
${ }^{1}$ O Programa Nacional do Álcool (PNA) ou Proálcool, lançado em 1975 pelo governo de Ernesto Geisel (19741979), foi o principal projeto de industrialização da agricultura promovido pela "ditadura militar", já que destinou créditos subsidiados (a juros reais negativos) ao setor sucroalcooleiro no montante de aproximadamente 7 bilhões de dólares até 1990 (TCU, 1990, p. 49), com o objetivo de ampliar a produção de álcool, fomentando a mecanização do setor e a industrialização do refino de cana-de-açúcar. O Proálcool foi objeto de estudo do mestrado de Pitta (2011), no qual ficou demonstrada a relação entre o Proálcool, como uma das políticas econômicas do Estado brasileiro para o campo, sua dívida externa e a inadimplência (TCU, 1990) dos capitais do setor sucroalcooleiro paulista. Nesta dissertação foi possível explicitar os impactos de tal política econômica como processo de modernização retardatária (KURZ, 1999), localizados por meio dos fenômenos de crise do final da década de 1980, com a "quebra" do Instituto do Açúcar e do Álcool, a falência de diversas usinas, a importante redução na produção de álcool combustível e de automóveis movidos a álcool; conseqüências da "crise das dívidas" (1982-1983), da hiperinflação nacional, e da "moratória" do Estado brasileiro (1986).

2 "Uma das primeiras medidas da desregulamentação, na verdade ocorrida já em 1989, foi a eliminação do monopólio público nas exportações de açúcar. De 1995 a 1999, aconteceu um processo escalonado de liberação de preços da cana-de-açúcar, do açúcar e do álcool, que até então eram fixados pelo governo. Ao mesmo tempo, deixava-se de tentar controlar diretamente a produção das unidades agroindustriais e das regiões, com a eliminação das quotas de produção e dos Planos de Safra. Até então as usinas e destilarias tinham a obrigação de apresentar, para aprovação do IAA, um plano anual que estipulasse qual seria o total de cana-de-açúcar a ser moída e as quantidades de açúcar e álcool a serem produzidas.

"Houve também mudanças importantes na comercialização do álcool. A partir da safra 1996/97 deixou de funcionar a mesa de comercialização do Governo Federal, que fixava o preço do álcool e procurava administrar as relações comerciais entre agroindústrias sucroalcooleiras, que, através de seus sindicatos, faziam suas ofertas de álcool, e as distribuidoras de combustíveis, representadas pelo Sindicato das Distribuidoras de Combustíveis (SINDICOM), que apresentavam seus pedidos de compra de álcool” (BACCARIN, 2006: 1).
} 
O Estado, ao desregulamentar a fixação de preços, mas determinar que a concorrência entre etanol e gasolina pudesse favorecer o primeiro, preparou as bases para um novo ciclo de expansão da agroindústria canavieira. Em entrevista realizada em 15 de dezembro de 2010, o ex-presidente da Associação Brasileira de Empresas de Leasing (ABEL), Rafael Cardoso, destacou que a economia com consumo de combustível que a retomada da produção de etanol iria oferecer para usuários de automóveis seria fundamental para o aumento do crédito pessoal e do financiamento para realização da indústria automobilística, dada a maior possibilidade de arcar com as parcelas dos financiamentos para compra de carros $^{3}$. Maiores facilidades de acesso ao crédito pessoal e ao endividamento da chamada "classe c" durante o governo Lula ocorriam concomitantemente ao aumento e rolagem da dívida interna, o que gerou a capacidade do governo de saldar os investimentos do sistema financeiro em seus títulos.

O fomento para a ampliação da oferta internacional de etanol partiu principalmente do BNDES (MILANEZ et al., 2008). Sob a perspectiva de que Estados Unidos, Japão e União Européia seriam potenciais consumidores ${ }^{4}$, enormes montantes de crédito foram destinados ao setor. Durante o governo Lula, o financiamento para a indústria da cana chegou a R \$ 28,2 bilhões. Em 2010, foram destinados R \$ 7,4 bilhões para financiar desde o cultivo ( $\mathrm{R} \$ 953$ milhões) até a produção de açúcar e álcool (R\$ 5,6 bilhões) e a co-geração de energia (R\$ 665 milhões). O montante destes empréstimos é maior do que o fornecido a outros setores da economia naquele ano, como as indústrias de papel, celulose e extrativista juntas (R \$ 3,1 bilhões), mecânica ( $\mathrm{R} \$ 5,3$ bilhões), metalúrgica ( $\mathrm{R}$ 4,9 bilhões), e têxtil e vestuário ( $\mathrm{R} \$ 2,1$ bilhões). Ao longo de 2008, em razão da crise financeira, até capital de giro das empresas em dificuldades financeiras foi financiado. Os valores são exorbitantes se comparados aos que o setor recebeu ao longo de todo o Proálcool em créditos subsidiados (com juros

\footnotetext{
${ }^{3}$ A opinião desse especialista revela a necessidade de demonstrar que uma relação causal entre fatos históricos não é suficiente para entendermos o movimento contraditório das determinações da forma mercadoria. $\mathrm{O}$ entrelaçamento entre consumo de automóveis, crescimento do crédito pessoal e consumo de etanol e gasolina é um ponto de crucial importância na retomada do crescimento de produção de etanol.

4 “A União Européia, por exemplo, formulou normas para redução da emissão de carbono através do consumo de combustíveis denominados "renováveis". A Diretiva 2009/28/CE, de maio de 2009 determina que até 2020 o bloco alcance uma cota de $20 \%$ de energias renováveis no consumo final bruto de energia e cada país-membro atinja a meta mínima de uso de $10 \%$ de energia renovável no setor de transportes. Isto garantiria a existência de um amplo mercado consumidor para o etanol brasileiro se este conseguisse se inserir na concorrência internacional deste tipo de combustível. Dentre as exigências para importação da Diretiva 2009/08/CE, estipula-se que os produtores não poderão promover a redução de área plantada com alimentos, nem o desmatamento de florestas protegidas. Não deverão utilizar mão-de-obra escrava nem infantil, deverão respeitar as associações sindicais e as práticas coletivas de negociação" (MENDONÇA et al., 2011).
} 
reais negativos) no montante de 7 bilhões de dólares de 1975 a 1990 (MENDONÇA et al., 2011).

Os esforços para dar ao etanol o status de commodity seguiam a tendência de aumento dos preços das mercadorias negociadas nos mercados de futuros, enquanto movimento especulativo de capitais ociosos que buscam se valorizar na circulação do mercado financeiro. Este aumento propiciou superávits na balança comercial brasileira e permitiu os pagamentos de saldos devedores a credores estrangeiros ${ }^{5}$. Tal pagamento promoveu também o aumento dos investimentos em títulos públicos negociados em reais, os de dívida interna, diferentemente do que ocorria entre 1975 e 1990, durante o Proálcool. Naquele período, houve a necessidade de gerar dívidas para pagar as dívidas externas anteriores, o que moveu uma política econômica que visava a substituição da matriz energética nacional.

\section{A expansão do monocultivo de cana}

Dados da $\mathrm{CONAB}^{6}$ (Companhia Nacional de Abastecimento) revelam que entre 2000 e 2011 a área ocupada por cana-de-açúcar saltou de 4,8 para 8,1 milhões de hectares. O processamento de cana-de-açúcar passou de 257,6 milhões de toneladas para 624,9 milhões de toneladas e a produção de etanol teve um aumento de 11 bilhões de litros para 27,669 bilhões de litros no mesmo período.

Recentemente se constata, com maior relevância nas regiões tidas como principais áreas de produção, um cenário de redução no ritmo de crescimento da produtividade. Na safra 2010/2011, a expansão territorial do monocultivo de cana foi de 9,2\% enquanto a produtividade (em ton/ha) cresceu somente $2 \%$. O segmento canavieiro aponta como motivos dessa queda alguns aspectos conjunturais, ligados principalmente a fatores climáticos como o excesso de chuvas na safra 2009/10, ou o prolongamento da estiagem em 2010/11. Essas questões de fato podem influir na diminuição da produtividade, entretanto essa explicação não é suficiente. A conjuntura

\footnotetext{
${ }^{5}$ O Brasil saldou sua dívida externa, securitizada na década de 1990, ao longo do século XXI. Para os dados e informações consultar Dívida pública: a experiência brasileira (SILVA et al., 2009).

${ }^{6}$ Para acessar tais dados ver MENDONÇA et al., 2011.
} 
de crise econômica mundial apresenta influência nesse processo, já que dificulta a aplicação de constantes investimentos na forma de insumos para manter a elevação dos níveis de produtividade. Desde o início dos anos 2000, a intensificação desses investimentos é sintomática, principalmente por meio da liberação de subsídios estatais.

A recente diminuição no ritmo de incremento da produtividade é acompanhada por um constante aumento da área plantada, evidenciando que esse modelo agrícola é necessariamente extensivo. Ou seja, o aumento de cana processada é resultado da extensão do monocultivo em "novas" áreas. Este processo deve ser compreendido a partir de um cenário de crise, já que o setor não tem capacidade de manter níveis de produtividade satisfatórios sem a apropriação de novos recursos naturais como terra e água. Portanto, a recente diminuição no ritmo de crescimento da produtividade se apresenta como mais um elemento a impulsionar a expansão territorial do capital canavieiro, em função da necessidade de elevar o total de cana produzida para suprir a demanda das usinas instaladas, muitas das quais funcionam aquém da capacidade total de processamento.

As plantações de cana-de-açúcar estão majoritariamente localizadas no CentroSul e no Nordeste. Estas regiões concentram $89 \%$ e 11\% da produção respectivamente. Na região Centro-Sul, o estado de São Paulo é o maior produtor com 54,23\% da área plantada, estimada em 4,3 milhões de hectares. Desde a safra de 2009/2010, a CONAB estima que a maior expansão ocorreu na região Centro-Oeste, principalmente em Mato Grosso do Sul (38,80\%) e Goiás (50,10\%) (MENDONÇA et al., 2011).

Estes números mostram que a região preferencial para a chamada "nova" expansão é o Cerrado, devido à existência de grandes bacias hidrográficas, que se constituem em elementos importantes para a agricultura extensiva, principalmente pela possibilidade de exploração de terras planas e fontes de água. Dados do Laboratório de Processamento de Imagens e Geoprocessamento (Lapig), da Universidade Federal de Goiás, indicam que o ritmo atual de desmatamento do Cerrado poderá elevar de $39 \%$ para $47 \%$ o percentual devastado do bioma até 2050 . A região é tão importante por sua riqueza em biodiversidade quanto a Amazônia, pois abriga cerca de 160 mil espécies de plantas e animais, muitas ameaçadas de extinção. A pesquisa demonstra ainda que a destruição do Cerrado coloca em risco o regime de chuvas e o volume dos rios no 
Pantanal e na Amazônia, pois estes biomas estão interligados (AGÊNCIA BRASIL, 2009).

A crise financeira de 2008 trouxe mudanças significativas para a agroindústria canavieira em relação ao padrão de expansão que se delineou nos anos anteriores. Além da diminuição no ritmo de crescimento da produtividade, podemos observar a internacionalização monopolista do setor, o aumento da dependência de créditos subsidiados, a expropriação de pequenos produtores e consequente substituição de lavouras alimentares, além do aumento da exploração da força de trabalho, como veremos adiante.

\section{$\underline{\text { A crise como expressão da autonomização do capital fictício }}$}

A crítica à forma mercadoria (MARX, 1983, L. I, vol. I, cap. I) como relação social fundamental dos sujeitos formados sob o capitalismo é uma possibilidade que tal contexto de crise nos proporciona. No momento de reprodução do capitalismo sob a égide do capital fictício (KURZ, 1995), as contradições de tal forma se desdobram como impossibilidade de acumulação capitalista pela exploração do trabalho (apesar de esta continuar a ocorrer), ou seja, da própria valorização do valor, em razão da alta composição orgânica dos capitais produtivos (MARX, 1983). As consequências, para os capitais investidos, aparecem como necessidade de gerar novas dívidas para pagar as anteriores. A impossibilidade de conseguir tais empréstimos levou às acentuadas fusões apresentadas pelo setor, após a crise de 2008, tendo como exemplo mais importante a constituição da Raízen, em 2010, uma joint-venture entre a Cosan e a Shell. Para os trabalhadores, a impossibilidade de vender sua força de trabalho se aprofunda conforme os desdobramentos críticos do processo histórico, forçando-os a se submeter a diversas formas de exploração.

Marx, em O Capital (1983), preocupou-se em criticar a concepção recorrente na economia política de positivar o crescimento econômico, demonstrando ser o devir histórico sob o capitalismo um processo contraditório. Ao elaborar sua crítica ao capitalismo, desvendou as distintas formas de contradição deste modo de produção, a 
começar pela forma mercadoria, sua expressão mais elementar ${ }^{7}$, e seu duplo aspecto contraditório: valor de troca e valor de uso. No capítulo I de O Capital, Marx analisa a forma da mediação social e a descreve como baseada na troca de mercadorias. No momento da troca se igualam duas coisas distintas. O que permite compará-las é justamente o valor, uma abstração social que se realiza (abstração real) apagando as diferenças entre as coisas trocadas (seus valores de uso), incluindo neste apagamento a própria diferença entre homens e coisas:

$\mathrm{Na}$ própria relação de troca das mercadorias, seu valor de troca aparece-nos como algo totalmente independente de seu valor de uso. Abstraindo-se agora, realmente, o valor de uso dos produtos do trabalho, obtém-se seu valor total (...). O que há de comum, que se revela na relação de troca da mercadoria (...), é, portanto, seu valor. (MARX, 1983, L. I; Tomo I: 47).

Marx (1983) desvenda os desdobramentos do duplo contraditório na reprodução capitalista a partir da "Lei Geral de Acumulação Capitalista" (MARX, 1983, I, t. I, cap. XXIII) entre capital, que se valoriza através da extração de mais-valia, e trabalho, o fundamento social (POSTONE, 1993) que produz valor. Conforme ocorre a acumulação do capital, o trabalho vivo é substituído por trabalho morto (capital constante), tornando cada vez mais crítica a própria valorização capitalista e gerando transformações nas formas de acumulação, observadas em momentos de crise. O "crescimento econômico", é, para Marx, forma de subjetivação naturalizada e positivada da objetividade social (o valor), não sendo esta a propriedade em si das mercadorias, mas uma relação social de dominação, apesar da aparência fetichista de satisfação das necessidades humanas pelos valores de uso.

A análise de Marx, que tem na mais-valia relativa o cerne dos desdobramentos da contradição da forma social, pode ser entendida como uma exposição lógica que, ao se objetivar, não se realiza sem percalços. Ou seja, não se pode dizer que as categorias do capital, enquanto conceito, estejam postas e se realizem ao mesmo tempo e em todos os espaços em que a lógica de tal conceito esteja universalizada (ALFREDO, 2008).

7 O Capital (MARX, 1983: 4) começa com a seguinte afirmação: “A riqueza das sociedades em que domina o modo de produção capitalista aparece como uma 'imensa coleção de mercadorias', e a mercadoria individual como sua forma elementar. Nossa investigação começa, portanto, com a análise da mercadoria". 
Justamente por isso, o tempo sob o capitalismo adquire uma característica específica, não linear, nem circular, mas sim caracterizado por rupturas, quebras e distensões ${ }^{8}$.

A modernização, entendida como expressão da totalidade do modo de produção capitalista, universaliza a sociabilidade da forma valor. O descompasso ou nãosimultaneidade que os Estados-nação tentam superar ao empreenderem processos de modernização retardatária (KURZ, 1999) evidenciam os limites para alcançar níveis de produtividade dos países centrais. A modernização é, entretanto, posta como objetivo nas trocas internacionais.

Segundo Marx (1983), é a mediação social da mercadoria que estabelece uma totalidade contraditória, condicionando as formas que tal contradição assume, apesar de aparentarem autonomia em relação a ela, já que são objetivadas na mercadoria desdobrada, o dinheiro. O duplo caráter da mercadoria (a contradição entre valor de troca e valor de uso) se autonomiza no dinheiro (MARX, 1983, III, t. II, cap. XLVIII: 269), que aparece como algo separado da forma social e é percebido como transhistórico. Desta maneira, o dinheiro aparece no capitalismo como qualquer outra mercadoria, contendo uma propriedade imanente natural, um valor de uso, o de autovalorização, de transformação de dinheiro em mais dinheiro. A fórmula D - D’ surge como momento plenamente fetichista da relação social mediada por mercadorias. É também o vínculo efetivo entre o momento lógico mais simples do capitalismo, a mercadoria, e o desdobramento mais completo da contradição da forma mercadoria.

Para Marx (1983, III, t. I, cap. XXI), a autonomização do dinheiro gera a possibilidade de "descolamento" do trabalho produtivo: "a única fonte efetiva de 'dinheiro que gera mais dinheiro', o consumo de trabalho abstrato na produção real de mercadorias, desaparece assim na 'forma sem conteúdo' da produção capitalista". Robert Kurz (1995) demonstra esta autonomização do dinheiro que, no processo social de valorização, desdobra-se em sua relação com o trabalho produtor de valor e com a terra, através do capital fictício (MARX, 1983, III, t. I, cap. XXV). Em sua função de

8 Ver Marx (1983, I, t. II, cap. XXIV): “A assim chamada acumulação primitiva”, que mostra a brusca ascensão econômica da burguesia após a Revolução Gloriosa na Inglaterra (1688), quando esta chega ao poder legislativo por meio da expropriação das terras de camponeses e incorporação de suas riquezas. 
meio de pagamento, o dinheiro pode ser utilizado para saldar dívidas sem que a valorização do capital tenha ocorrido, postergando-a ao futuro.

A acumulação desses compromissos ao nível do capital global alimenta uma possível crise, que pode aparecer no momento em que os devedores não consigam pagar o que devem, como na crise financeira de 2008, tendo que renovar suas dívidas com novos financiamentos. A necessidade do financiamento bancário para a crescente substituição do trabalho vivo por capital constante no processo produtivo teve como consequência a dificuldade em pagar os compromissos creditícios assumidos, o que fez com que a necessidade de novos financiamentos para a reprodução ampliada da produção aumentasse ainda mais a dependência em relação ao capital fictício e, assim, aprofundasse a crise no processo de valorização do valor. Tal forma fictícia do capital passou a funcionar como adiantamento da realização da valorização que nunca chegará a ocorrer, o que caracteriza um momento particular da reprodução social. O capital fictício, por isso, passou a determinar a necessidade da produção de mercadorias e do aumento da produtividade, sendo esta inversão a característica particular desse momento, e o próprio aprofundamento tautológico da crise. Assim, o capital fictício funciona como uma dominação social objetiva e fantasmagórica sobre a totalidade da sociedade produtora de mercadorias ${ }^{9}$.

A modernização retardatária brasileira ocorre, portanto, através de créditos subsidiados pelo Estado e inclui processos produtivos agrícolas através do uso de insumos químicos (como fertilizantes, inseticidas e herbicidas) e da mecanização ${ }^{10}$. Este processo gerou aumento na composição orgânica dos capitais agrícolas e colocou a valorização crítica em um novo momento, em razão do que Marx chamou de queda tendencial da taxa de renda da terra (MARX, 1983, L.III, Vol. I, Seção VI). A

\footnotetext{
9 "O trabalho, como dispêndio abstrato de energia humana no processo da racionalidade empresarial, e o dinheiro, como forma fenomênica do valor econômico [...] são as duas faces da mesma moeda. O dinheiro representa ou 'é' nada mais que trabalho morto, tornado realmente abstrato na forma duma coisa que consiste numa acumulação sempre acrescida de tal meio fetichista. Como o trabalho e o dinheiro constituem fases diferentes do desenvolvimento da valorização como fim em si mesmo, estes dois momentos também podem separar-se em situações de crise, deixando assim de coincidir. Tal falta de coincidência manifesta-se como desvinculação entre o dinheiro e a substância abstrata do trabalho: a multiplicação do dinheiro ocorre então mais rapidamente que a acumulação de trabalho morto abstratizado, destacando-se assim de sua própria base" (KURZ, 1995: 1).

10 A automação na produção de cana hoje chega ao nível de não se precisar mais nem do motorista do trator ou colhedeira, já que estes podem ser controlados por mecanismos vinculados a um GPS (Global Positioning System). Isto nos mostra que a própria substituição de trabalho vivo por morto continuou a ocorrer, chegando a um patamar muito elevado, mesmo para tratoristas e motoristas, após a expansão da agroindústria canavieira no início do século XXI.
} 
rentabilidade destes capitais depende da existência continuada de empréstimos, seja pela transferência de mais-valia social através do aparelho estatal ou de capitais privados ociosos em busca de valorização. Essa busca por possibilidades de explorar trabalho e renda da terra relaciona-se com a própria crise de valorização do capital, o que nos leva a analisar a agroindústria canavieira brasileira no contexto da atual crise financeira mundial.

O setor sucroalcooleiro no Brasil passou por diversas crises fenomênicas em sua história, porém com características distintas. Na segunda metade dos anos 1980, a crise no setor se caracterizou pela falta de álcool nos postos de abastecimento e pela elevação de seu preço, tornando-o não competitivo em relação à gasolina. Foram os subsídios estatais para o Proálcool que permitiram o fomento da produção de etanol e de carros movidos por este combustível. O Relatório do Tribunal de Contas da União de 1990, que investigou as dívidas do setor, tentava avaliar as causas de tal crise, destacando que o fim dos créditos subsidiados oferecidos pelo governo havia levado muitas empresas à bancarrota. Ao final daquele ciclo modernizador, tanto as empresas quanto o Estado foram incapazes de saldar suas dívidas, o que gerou moratórias, hiperinflação e recessão.

O mais recente ciclo de modernização da agroindústria canavieira no Brasil durou cerca de cinco anos, de 2003 até a crise financeira de 2008. A diferença em relação ao ciclo anterior é que o crédito nesse momento não desfruta de um programa voltado especificamente para a agroindústria canavieira, que conta com a participação do crédito privado e de empréstimos do BNDES. A constante demanda por crédito e "rolagem" das dívidas no setor canavieiro se caracteriza como parte do momento crítico de reprodução do capital global e se expressa por meio dos fenômenos localizados de crise.

Como resultado da crise financeira de 2008, diversas usinas não conseguiram financiamento para saldar suas dívidas e deixaram de pagar o que deviam a seus credores, mas também a seus fornecedores de cana. Estes, por sua vez, também não conseguiram saldar suas dívidas (principalmente as maiores, relacionadas à compra de 
tratores e colhedeiras), o que os impediu de conseguir novos empréstimos, levando muitos à falência ou à incorporação por outros grupos ${ }^{11}$.

Nas fazendas do grupo Bulle Arruda S.A. Agropastoril ${ }^{12}$ (em Olímpia, Monte Verde e Cajobi, no estado de São Paulo), por exemplo, seus acionistas colocaram à venda as propriedades produtoras de cana-de-açúcar, e receberam proposta de compra do grupo francês Tereos, co-proprietário das usinas Guarani (sócia da Petrobrás), com diversas unidades na região. A estrutura de capital constante para a mecanização da colheita de cana do Grupo Bulle Arruda S.A. saltou de 30\% para 99\% entre 2008 e $2009^{13}$, caracterizando um alto montante de investimento para o setor. Vale ressaltar que o grupo Bulle Arruda era credor de uma usina do grupo Equipav, em Lins, região onde haviam arrendado terras para o fornecimento de cana. Como essa usina não pagava suas dívidas, a empresa teve que vender suas propriedades. Em 2009, o Grupo Equipav S/A foi comprado pela multinacional indiana Shree Renuka. Este negócio é representativo do processo atual de entrada de multinacionais no setor ${ }^{14}$.

\section{$\underline{\text { A crise financeira e a concentração de capitais }}$}

O movimento de aprofundamento da concentração de capitais na produção de etanol está relacionado aos impactos da crise financeira de 2008. A possibilidade de rolagem de dívidas por empresas nacionais, como fizeram historicamente, foi prejudicada pela escassez de crédito em um período de crise, o que estimulou o processo de fusão e aquisição de usinas brasileiras por grupos estrangeiros. As fusões realizadas por grupos do próprio setor em um movimento de concentração também

\footnotetext{
${ }^{11}$ Tal constatação resulta de dados da CONAB sobre a produção de cana nas últimas safras, de notícias divulgadas na mídia e análises sobre o setor. Ver, por exemplo, as seguintes notícias sobre a crise do setor, entre 2008-2009: "Usina pede recuperação judicial por causa da crise" (Folha de São Paulo, 2008); "Usinas de álcool dão calote no fisco em São Paulo" (Folha de São Paulo, 2009); "Setor sucroalcooleiro do Brasil tem pausa após grande expansão" (Folha de São Paulo, 2009). Nesta última encontramos: "Segundo dados da Datagro, estima-se que quase metade do setor tenha ficado próximo da falência, especialmente as empresas que já estavam muito endividadas e que sofriam com os preços baixos do açúcar e do etanol nos anos anteriores".

12 Acompanhamos as atividades deste grupo de fornecedores de cana em trabalhos de campo. Visitamos a área de Olímpia-SP em quatro ocasiões, antes e depois da crise de 2008. Investigamos também a incidência dos créditos subsidiados do Proálcool na Usina Guaraní (com unidade em Severínia), de quem o Grupo Bulle Arruda é fornecedor.

13 Segundo estimativas do próprio grupo, fornecidas por sua diretora Lenita Arruda Boechat, em entrevista realizada em 24 de julho de 2009.

${ }^{14}$ Para tal tendência, particularmente a joint-venture Cosan-Shell, ver Mendonça et al., 2011.
} 
foram relevantes no período em que se expandiu a produção internacional de carros flexfuel, tendo se acentuado após a crise de 2008.

A participação de empresas estrangeiras na indústria da cana no Brasil cresceu de $1 \%$ em 2000 para cerca de $30 \%$ em 2010. Uma característica do setor é a aliança entre setores do agronegócio com empresas petroleiras, automotivas, de biotecnologia, mineração, infra-estrutura e fundos de investimento. Neste cenário, não existe nenhuma contradição destes setores com a oligarquia latifundiária, que se beneficia com o abandono de um projeto de reforma agrária.

Um caso emblemático foi a entrada da petroleira Shell na produção de etanol, a partir da constituição de uma joint venture com o Grupo Cosan, formando a empresa Raízen. Esta controla atualmente 24 usinas na região Centro-Sul. Ao divulgar a operação, a nota da Shell afirma que sua intenção seria criar "um rio de etanol, correndo desde as plantações no Brasil até a América do Norte e a Europa” (THE TIMES, 2010).

Além da holandesa Shell, estão presentes hoje no setor sucroalcooleiro brasileiro as seguintes empresas estrangeiras, que juntas são proprietários de mais de 100 usinas (em ordem alfabética): Açúcar e Álcool Fundo de Investimento e Participações (constituído por fundos de investimento Carlyle/Riverstone, Global Foods /Goldman Sachs /Discovery Capital e DiMaio Ahmad), Abengoa (Espanha), Adecoagro (do grupo Soros, EUA/Argentina), ADM (EUA), Brazil Ethanol (EUA), British Petroleum (Inglaterra), Bunge (EUA), Cargill Inc (EUA), Clean Energy (Inglaterra), Glencore (Suíça), Infinity Bio-Energy (Inglaterra e outros, controlado pelo Bertin), Louis Dreyfus (França), Mitsubishi (Japão), Mitsui (Japão), Noble Grouptinha (China), Shree Renuka Sugars (Índia), Sojitz Corporation (Japão; tem $65 \%$ da ETH, uma sociedade com a Odebrecht), Sucden (França), Kuok (China), Tereos (França) e Umoe (Noruega).

Outros exemplos de fusão que ocorreram recentemente incluem:

- Em 2009, a empresa petroleira britânica British Petroleum (BP) anunciou que iria produzir etanol no Brasil, com um investimento de US\$ 6 bilhões de dólares nos próximos dez anos. A BP deve atuar através da Tropical Bioenergia, em associação com o Grupo Maeda e a Santelisa Vale, em Goiás, que contam com uma área de 60 mil hectares para a produção de cana no estado. 
- Em julho de 2009, a Syngenta divulgou a aquisição de terras para produzir mudas de cana-de-açúcar na região de Itápolis (SP). O projeto inclui a produção de mudas transgênicas e pretende se expandir para outros estados, como Goiás, Minas Gerais, Paraná e Mato Grosso do Sul.

- No início de 2010, ocorreram novas fusões. Em janeiro, a multinacional agrícola Bunge anunciou a compra de quatro usinas do Grupo Moema, incluindo a usina Itapagipe que tinha participação acionária de 43,75\% da empresa norte-americana Cargill. Com a negociação, a Bunge passará a controlar $89 \%$ da produção de cana do Grupo Moema, estimada em 15,4 milhões de toneladas por ano.

- Em fevereiro de 2010 foi anunciada a fusão da ETH Bioenergia, do grupo Odebrecht, com a Companhia Brasileira de Energia Renovável (Brenco), que pretende se tornar a maior empresa de etanol no Brasil, com capacidade para produzir três bilhões de litros por ano. Alguns dos acionistas da Brenco são Vinod Khosla (fundador da Sun Microsystems), James Wolfensohn (ex-presidente do Banco Mundial), Henri Philippe Reichstul (ex-presidente da Petrobrás), além da participação do BNDES.

- A Odebrecht tem sociedade com a empresa japonesa Sojitz. O novo grupo irá controlar cinco usinas: Alcídia (SP), Conquista do Pontal (SP), Rio Claro (GO), Eldorado (MS) e Santa Luzia (MS). O conglomerado ainda participa da construção de um alcoolduto entre o Alto Taquari e o porto de Santos e pretende instalar usinas na África. A empresa tem intenção de captar R \$3,5 bilhões até 2012, dos quais pelo menos $20 \%$ virão do BNDES, além de outros $\mathrm{R} \$ 2$ bilhões que o banco já investiu anteriormente na Brenco.

\section{Financiamento público e subsídios}

As usinas de cana-de-açúcar historicamente dependeram de diversas formas de subsídio estatal. Ao verificarmos a incapacidade de reprodução do setor sem o acesso ao crédito, encontramos relações fundamentais entre dois momentos de crise. Nosso estudo busca entender como muitas usinas puderam retomar acesso a crédito após as falências do final dos anos 1980 (THOMAZ JR. 2002) e da "desregulamentação" dos anos 1990 (BACCARIN, 2005), principalmente para conseguir financiar a "expansão" da produção de etanol no século XXI. 
Diversos autores explicitam a existência de créditos subsidiados ao setor, historicamente e até os dias atuais, incluindo o contínuo perdão de dívidas. O professor de economia da UNICAMP (Universidade de Campinas), Pedro Ramos, ressalta inclusive que a obrigatoriedade de acréscimo de etanol à gasolina, mesmo quando os preços deste sobem, pode ser considerada como uma forma de subsídio. Thomaz Jr. (2002) mostra os sucessivos perdões às dívidas da agroindústria canavieira como comprovação dos "benefícios" que desfrutam. Para o autor, fica explícita a incapacidade de diversas usinas deixarem de ser inadimplentes.

Em agosto de 2008, o governo brasileiro decretou a substituição da taxa SELIC (13\% ao ano naquele momento) pela Taxa de Juros de Longo Prazo (6,25\% ao ano) para a negociação de R $\$ 75$ bilhões de dívidas do setor agrícola, provenientes das décadas de 80 e 90. Este montante se aproxima dos R $\$ 65$ bilhões destinados ao investimento no agronegócio pelo Plano Agrícola de 2008/2009, também divulgado em agosto, que representou um aumento de $12 \%$ em relação ao ano anterior e manteve taxas fixas de juros a 6,75\% ao ano (RAMOS, 2011).

Essa política de renegociação de dívidas do setor agrícola apareceu também em outros governos na história recente da modernização brasileira, especialmente no que tange ao setor sucroalcooleiro. Em 1991, durante o governo Collor, um relatório da Secretaria de Desenvolvimento Regional/ Departamento de Assuntos Sucroalcooleiros (SDR/DAS) definiu o "Plano de Socorro aos Usineiros Endividados", que permitiu a rolagem das dívidas e novas linhas de crédito. No "Plano Collor II", durante o chamado "Tarifaço", o setor foi o único a ser contemplado com 46,7\% de aumento dos preços, sendo que, de março de 1990 até fevereiro de 1991, o aumento acumulado atingiu 671,4\%, enquanto o BTN variou em 242,5\% (THOMAZ JR., 2002). No governo de Itamar Franco, em 1994, foi concedida uma nova linha de subsídios ao setor sucroalcooleiro de US\$ 1,17 bilhões, através do chamado "Plano Socorro"15.

Outros autores buscam destacar que os subsídios para a reprodução do setor são implícitos. Por exemplo, a monografia de OGATA (2009) procura ressaltar a continuidade de subsídios indiretos e "disfarçados" para o etanol em razão da cobrança

\footnotetext{
${ }^{15}$ Ver dados em Thomaz Jr. (2002).
} 
de percentagens maiores de ICMS (Imposto Sobre Circulação de Mercadorias e Serviços) e CIDE (Contribuição de Intervenção no Domínio Econômico) para a venda da gasolina. Esta operação garante a competitividade do etanol e sua realização no processo de circulação enquanto mercadoria. No estado de São Paulo, por exemplo, enquanto o etanol paga 12\% de ICMS a gasolina deve recolher 25\% (OGATA, 2009: 40).

Atualmente, diversas empresas apresentam balanços contábeis lucrativos utilizando como referência a EBITDA (Earnings before interest, taxes, depreciation and amortization - Lucros antes de juros, impostos, depreciação e amortização). Este cálculo é uma forma de escamotear a insolvência das empresas no momento em que necessitam de crédito. Consideramos este mecanismo como forma de "escamotear" a situação financeira das usinas, a partir da análise de Ramos (2011), que destaca a mudança na forma que os financiamentos do Estado assumiram ao longo dos anos 1990 e 2000, o que permitiu que o governo concedesse empréstimos para o setor sucroalcooleiro apesar da insolvência de algumas usinas:

Face às dificuldades que o setor vem enfrentando, que decorrem em boa medida dos elevados investimentos que vêm recebendo, principalmente quando relacionados às frustradas expectativas de expansão dos seus dois mercados principais (com destaque no tocante às exportações de álcool carburante), o Governo Federal tem buscado dar novo apoio aos produtores na forma de novo suporte financeiro para o armazenamento de álcool. Sobre isto é revelador o que disse o presidente da Única, ao destacar a importância de tal medida: "Isso permitirá que a próxima safra não seja tão açucareira, pois passa a ser interessante estocar álcool com financiamento público". Tal financiamento deverá ficar sob responsabilidade do BNDES e do Banco do Brasil, sendo que a diferença entre as taxas de juros de captação e de concessão poderão implicar uma perda de recursos que será coberta com subsídio do Tesouro (RAMOS, 2011: 17-18).

As diversas formas de crédito subsidiado para o setor, que incluem desde o plantio de cana até a estocagem de etanol, demonstram a atuação do capital fictício para viabilizar a reprodução da indústria da cana. As transformações ocorridas na forma de reprodução fictícia do capital fazem com que as empresas e o próprio Estado pareçam solventes já que, para conceder crédito, o Estado necessita captar dinheiro na forma de crédito. 
Podemos inferir que a diferença da taxa básica de juros que o Estado paga para esta captação (denominada Taxa SELIC) e os juros cobrados para empréstimo pelo BNDES, se constitui em subsídio" ${ }^{16}$, implicando "uma perda de recursos que será coberta com subsídio do Tesouro" (RAMOS, 2011). Segundo o autor, os empréstimos do BNDES para a agroindústria canavieira, principalmente para a mecanização do corte de cana ao longo do século XXI, configuravam uma dívida das usinas no montante de 40 bilhões de reais em 2009 (RAMOS, 2011: 17). Este recurso é equivalente a dois terços do que o BNDES concedeu à produção agrícola em 2007.

Estes dados mostram que a reprodução do setor se realiza a partir de créditos subsidiados, através de mudanças na forma de o Estado conceder subsídios em relação ao período do Proálcool, quando os juros dos empréstimos eram menores do que a taxa da inflação. Se, ao longo do Proálcool, a dívida externa era o fator determinante de sustentação da reprodução das relações sociais de produção (LEFEBVRE, 1974), tal dívida deixou de ser relevante a partir do primeiro governo Lula (2002 - 2005), quando o Brasil adquiriu reservas em dólares em um montante maior que a própria dívida, podendo, assim, saldá-la. A passagem da dívida externa para a interna como forma de criação fictícia de dinheiro (ou seja, dinheiro autonomizado do processo de valorização - MARX, 1983) é característica central deste processo. Esta transformação, conforme elucida Belluzzo (2009: 25), ocorreu com o chamado processo de "securitização" das dívidas, quando os credores puderam passar a negociar os títulos de dívida de Estados e empresas. Com isso, diversas instituições, e inclusive pequenos investidores, podem investir em fundos que têm em sua "carteira" as dívidas de países e empresas. O setor sucroalcooleiro também teve suas dívidas "securitizadas" ao longo dos anos 1990 (RAMOS, 2011). Este tipo de mecanismo financeiro aumentou a capacidade de circulação de capital fíctício, o crescimento de sua base monetária e suas determinações sobre o processo produtivo (ALFREDO, 2010).

\section{Expansão territorial da lavoura canavieira}

\footnotetext{
16 "Relatório Final da Comissão Parlamentar de Inquérito (CPI) destinada a investigar a dívida pública da União, Estados e Municípios, o pagamento de juros da mesma, os beneficiários destes pagamentos e o seu impacto nas políticas sociais e no desenvolvimento sustentável do País" (NOVAIS, 2010).
} 
Os investimentos na agroindústria canavieira, a partir do século XXI, estimularam a mecanização do corte de cana e o aumento da produtividade da parte agrícola e industrial do setor, elevando, consequentemente, a produção de cana, açúcar e álcool. Este aumento esteve acompanhado por mudanças nas relações sociais de produção. A partir desta análise, observamos a incorporação da renda da terra por meio do movimento de territorialização do capital, através da incidência de créditos, como mostra Thomaz Jr:

A obtenção de ganhos adicionais mediante diferentes modalidades da renda da terra cativa o capital quanto ao empreendimento da territorialização da sua expansão, para viabilizar o empreendimento agroindustrial (produção agrícola e processamento industrial). Sem contar que é a agressividade da apropriação do território que lhe possibilita mudar as funções e as formas de uso e exploração da terra, de maneira mais ou menos radical, neste limiar do século XXI, seja oriunda, inicialmente, do desmatamento ilegal e destrutivo das florestas naturais, de posseiros, índios, grileiros, seja de pastagens, da laranja, das culturas da lavoura branca etc. (THOMAZ JR., 2009: 264).

É significativo o movimento de territorialização, com aumento de financiamentos para expansão da produção e produtividade, no momento que antecedeu a crise de 2008. Este pode ser interpretado como incorporação da Renda da Terra por meio de expropriação para viabilizar a acumulação, como sugere Thomaz Júnior (2009). Em relação à área plantada temos um aumento também horizontal, incorporando pequenas propriedades (THOMAZ JR., 2009), mesmo após 2008. Assim, parece que é a incorporação da Renda da Terra Diferencial I, com a introdução de solos piores, que caracterizaria tal movimento. A comparação entre a produtividade da DIRA (Divisão Regional Agrícola) de Ribeirão Preto e de Presidente Prudente (onde está a maior parte do Pontal do Paranapanema) é representativa de tal característica, já que esta se localiza em áreas mais ao oeste do Estado, permitindo a expansão da fronteira da cana, o que pode explicar a diminuição de sua produtividade ${ }^{17}$.

17 Vale explicitar a diferença de tal movimento e a expansão extensiva promovida pelo Proálcool, que buscou compensar a queda na renda da terra adquirida nos solos mais produtivos devido aos altos custos de investimentos para manutenção da taxa de renda da terra. Naquele momento, a redução desta última tentava uma solução pela ampliação da área produzida com menor produtividade, de modo a compensar a perda da taxa em solos mais produtivos. $\mathrm{O}$ aumento do preço devido a um solo regulador menos produtivo acrescentaria renda da terra ao mais produtivo. Tratou-se daquilo que Marx observa como a expansão da renda da terra em ziguezague (Marx, 1983. L. III, vol. I, Seção VI: "Metamorfose do Sobrelucro em Renda Fundiária") tanto de solos mais produtivos para os menos, como vice-versa. 
Os dados do Instituto de Economia Agrícola (BRESSAN, 2010) nos mostram tal característica $^{18}$. A produtividade na DIRA de Ribeirão Preto, maior e antiga produtora do estado, aumentou de 78 ton/ha, em 2004; para 83 ton/ha, em 2010. Na de Presidente Prudente caiu de 83 ton/ha, em 2004; para 77 ton/ha, em 2010. Já a expansão da área colhida com cana, para as duas DIRAs, respectivamente, no mesmo período, foi de 388.308,00 ha, em 2004, para 477.948,00 ha, em 2010; e de 140.083,00 ha, em 2004; para 443.663,00 ha, em 2010. Entretanto, a expansão da lavoura canavieira, enquanto forma de incorporação de um sobrelucro à acumulação capitalista a partir da renda da terra, não foi capaz de permitir que os proprietários fornecedores de cana, e tampouco as usinas de açúcar e etanol, liquidassem suas dívidas. A possibilidade desta afirmação se baseia na incapacidade do setor se reproduzir quando da inviabilidade de aquisição de novas dívidas. Assim, parece que sem a rolagem de dívidas a reprodução ampliada do setor não se realiza, ficando para nós a questão acerca da ficcionalização de tal reprodução, quando do momento de crescimento que antecedeu a crise de 2008.

\section{Relações de trabalho no monocultivo de cana}

$\mathrm{O}$ alto índice de endividamento e inadimplência das usinas, que dependem de recursos públicos, está relacionado com a superexploração do trabalho. A suposta "competitividade" do etanol brasileiro no mercado externo é baseada na exploração de mão-de-obra, em subsídios estatais e em diversas formas de apropriação de recursos naturais, incluindo a grilagem de terras.

O modelo adotado historicamente do setor, baseado no pagamento dos cortadores de cana por produção e não por hora de trabalho, gera uma condição estrutural degradante para os trabalhadores. Portanto, a superexploração do trabalho não ocorre de forma pontual ou isolada, mas de maneira sistemática no monocultivo da cana. As empresas, ao avançarem no processo de mecanização do corte, aproveitam para veicularem um discurso de modernização do setor, na tentativa de melhorar sua imagem junto à opinião pública, principalmente para obter acesso ao mercado externo.

\footnotetext{
${ }^{18}$ Cabe destacar que tal formulação tem a intenção de ser apenas um exemplo. Para considerar o custo de produção, o preço final do produto e da terra, ver dados em BRESSAN, 2010.
} 
Porém, nas regiões onde prevalece o corte mecanizado, como no estado de São Paulo, pioram as condições de trabalho, pois os cortadores necessitam atingir uma cota de produtividade cada vez maior para garantir seu emprego. Além disso, as empresas utilizam a mecanização como chantagem para evitar que os cortadores reivindiquem melhorias de salário e condições de trabalho. Essa função é estruturalmente degradante, pois exige muito esforço físico. Diversos são os relatos de doenças, acidentes de trabalho, casos de trabalho escravo e até mortes por exaustão, conforme destacaremos adiante. Como o pagamento é feito por produção, o trabalhador é impelido a cortar cada vez mais para tentar cumprir uma cota que cresce com a mecanização, dada a iminência do desemprego no setor. Os processos de mecanização e superexploração do trabalho aparecem estritamente relacionados.

A produção de cana-de-açúcar, principalmente a partir dos créditos subsidiados do Proálcool, passou a ter diversas de suas etapas mecanizadas. Assim, o número de trabalhadores necessários para o plantio e os tratos culturais foi reduzido ao longo das décadas de 1970 e 1980. Já a mecanização do corte apenas passou a apresentar crescimento significativo a partir do século XXI. Um dos principais impactos da mecanização foi em relação à violação dos direitos dos trabalhadores, incluindo dezenas de mortes no corte de cana, principalmente após o uso de colhedeiras ter se tornado preponderante.

No estudo Errantes do fim do século, Maria Aparecida de Moraes Silva (1999) analisou as conseqüências da mecanização da lavoura canavieira no que diz respeito às relações de trabalho. Uma das estratégias utilizadas pelos usineiros para não arcar com os direitos trabalhistas é a manutenção do regime de contrato temporário, através de intermediários, conhecidos como "gatos" ou empreiteiros (termo atualmente utilizado), que arregimentam a mão-de-obra migrante que prevalece nos canaviais. Para tanto, o chamado "gato", ou seja, a terceirização da arregimentação e do controle do processo de trabalho de cortadores de cana é um elemento fundamental nesta estratégia. Sua função inclui transportá-los de suas cidades de origem para as usinas, assim como se responsabilizar pelo cumprimento das metas de produtividade do cortador (ou seja, da quantidade de toneladas de cana cortada por dia). 
O transporte, quando no caso dos migrantes, é feito de forma improvisada, muitas vezes ilegal, além de gerar "dívidas" para os trabalhadores, que precisam pagar por despesas de viagem, alojamento, comida, e outros custos incompatíveis com seu salário, que aumentam quando se encontram longe de seus locais de origem. Dessa forma, os trabalhadores já chegam endividados e esse é um dos mecanismos utilizados para mantê-los no corte da cana, mesmo em condições degradantes.

O sistema de corte é basicamente o mesmo desde a década de 1960 até os dias de hoje, com o pagamento feito em toneladas de cana a partir da metragem cortada, e a tonelagem de cada metro calculada nas balanças da usina. Silva (1999: 108) destaca o que chamou de "pulo do gato": uma percentagem da produção do trabalhador em salário se torna o salário do "gato". Porém, tal interesse direto do "gato" no aumento da produtividade do trabalho não é a única estratégia das empresas para aumentar seus lucros. Os cortadores não têm acesso à transformação dos metros cortados em toneladas ${ }^{19}$, podendo aí, tanto a usina quanto o "gato", ficar com parte da produção que deveria ser paga aos cortadores. Além disso, as usinas usam o "gato" como intermediário no registro dos trabalhadores para tentar se desobrigar da responsabilidade pelos descumprimentos dos direitos trabalhistas.

Atualmente, muitos cortadores recebem equipamentos de proteção e têm sua carteira assinada em regime temporário por safra (o que lhes permite cobrar seus direitos ao final de cada período trabalhado). Mesmo assim, os casos de descumprimento de leis trabalhistas são recorrentes, tanto em São Paulo como nas demais regiões do Brasil (SILVA, 2008). A regulamentação da contratação pode ser entendida, portanto, como tentativa das empresas de apresentar uma boa imagem, principalmente para a opinião pública internacional. As diversas denúncias de descumprimento de leis trabalhistas levaram as empresas a buscar diferentes formas de escamotear a superexploração do trabalho.

\footnotetext{
${ }^{19}$ Em todo o Brasil, o único sindicato de trabalhadores rurais que conseguiu negociar o direito de monitorar a pesagem da cana está localizado no município de Cosmópolis (SP). Mesmo nessa região, nossas entrevistas com os trabalhadores revelam que a usina manipula o preço do tipo de cana cortada. Por exemplo, deixa de pagar o adicional referente ao corte da chamada "cana deitada" (rente ao chão), que exige maior esforço físico do que a cana reta. As entrevistas estão disponíveis em: http://www.social.org.br/revista-monopolio.pdf.
} 
Um exemplo dessa estratégia pode ser encontrado no Compromisso Nacional para Aperfeiçoar as Condições de Trabalho na Cana-de-Açúcar (2009), lançado em junho de 2009. O cumprimento do Compromisso e a maneira de avaliá-lo, porém, continuam em estágio inicial de debates. Este tipo de acordo não tem efeito prático, já que não há monitoramento ou punição adequada no caso de descumprimento. A Secretaria-Geral da Presidência da República, que administra o acordo, confirmou que ao menos 248 usinas (das mais de 300 que manifestaram intenção inicial de aderir ao acordo, em meados de 2009) preencheram o cadastro de adesão. Esse registro só assegura às companhias solicitantes a condição de aptas para a verificação in loco, conforme frisa a assessoria de imprensa da pasta: "Só serão reconhecidas as empresas que efetivamente tiverem comprovação do cumprimento dos compromissos, mediante auditoria externa".

Segundo o relatório O Etanol Brasileiro no Mundo - Os impactos SócioAmbientais Causados por Usinas Exportadoras (Repórter Brasil, 2011:6), “Ainda não se sabe, porém, como será feita essa auditoria. Também não há prazos. (...) Foram tantas as idas e vindas que o prazo inicial de dois anos estabelecido para o Compromisso se encerrou em junho de 2011 sem que quase nada tenha efetivamente se concretizado (...) Empresários e articuladores do governo querem simplesmente prorrogar o que foi celebrado em 2009”. Fica evidente que o Compromisso não está sendo cumprido, mas interessa às empresas como maneira de prolongar as condições degradantes de trabalho.

Com a intensificação do uso de máquinas colhedeiras, a participação do corte manual diminui a cada safra. Estima-se que 60\% da área plantada em São Paulo seja colhida com máquinas, onde o número de cortadores caiu $8,8 \%$ entre 2009 e 2010, sendo atualmente cerca de 140,4 mil. Em relação a 2007, o recuo chega a 21,1\%, segundo o boletim Ocupação Formal Sucroalcooleira em São Paulo, produzido por pesquisadores da Universidade Estadual Paulista em Jaboticabal (SP). A redução do corte manual não foi maior porque o nível de mecanização nas novas áreas de expansão da cana em São Paulo é inferior, pois utilizam tanto o corte manual quanto o mecanizado (BACCARIN, 2011).

A continuidade dos casos de descumprimento dos direitos trabalhistas permitenos demonstrar que a reiteração do processo de mecanização do setor não os extinguiu, 
mas apenas os repôs em outros patamares. O papel do "gato" ou "empreiteiro" ainda existe $^{20}$. Ou seja, a prática da terceirização continua a ocorrer, assim como a superexploração do trabalho, o rebaixamento constante dos salários, o pagamento por produtividade, entre outras violações de direitos trabalhistas. ${ }^{21}$

Ao analisarmos a elevação da produtividade do trabalho, constatamos o aumento da exploração dos trabalhadores (RAMOS, 2007). A elevação de produtividade - de 3 toneladas por dia, em 1970, para 6 toneladas por dia, em 1990 - se atrela a uma concorrência cada vez mais acirrada entre trabalhadores e a substituição do trabalho no processo produtivo, impelindo-os a cortar cada vez mais e a receber menos por tonelada de cana. A redução dos salários não ocorre atualmente apenas como pagamento inferior aos acordos entre patrões e sindicatos (o que continua a acontecer), mas também porque tais acordos permitem a diminuição do pagamento por tonelada de cana. Este processo se acentua conforme o aumento da mecanização do corte de cana. Se, em 1970, um trabalhador recebia o equivalente a $\mathrm{R} \$ 2,00$ por tonelada de cana cortada e, em 1990, R\$ 0,96; em 2005 a tonelada de cana paga valia $\mathrm{R} \$ 0,86$.

A pressão exercida sobre o trabalhador para aumentar sua produtividade revela uma forma típica de exploração nas usinas. As empresas deixam de contratar os cortadores que não alcançam metas cada vez maiores de produção, que atualmente variam de 10 a 15 toneladas de cana por dia. O uso crescente das colhedeiras leva a um aumento constante da concorrência entre os cortadores e, conseqüentemente, ao aumento da produtividade do trabalho. Segundo o professor Pedro Ramos, em 1977 a média diária era de 3,77 toneladas, passando a 5 toneladas em 1985, 7 toneladas em 1998, chegando a 8 toneladas em 2005 (RAMOS, 2007: 16).

Os relatos de câimbra generalizada pelo corpo seguida de morte em razão de esforço excessivo no trabalho - tendo ocorrido 17 mortes nos canaviais paulistas nas safras 2004/2007 (RAMOS, 2007, p. 16) - denunciados pelo Serviço Pastoral do Migrante, de Guariba, e pela Rede Social de Justiça e Direitos Humanos (2009),

\footnotetext{
${ }^{20}$ Apesar do salário do "gato" ainda estar vinculado à produtividade dos cortadores (o que o estimula a fomentar seu aumento), há situações em que não é ele o responsável pelo pagamento, o que diminui seu poder de manipulação. Essa manipulação passa então a ser feita pelas próprias usinas.

${ }^{21}$ Ver entrevistas com trabalhadores em: http://www.social.org.br/revista-monopolio.pdf.
} 
passaram a ser frequentes no trabalho do corte de cana, assim como casos de doenças e mutilações. Portanto, não é o "atraso" do setor que leva aos casos de descumprimento dos direitos trabalhistas, já que mesmo com a preponderante mecanização do corte os casos se perpetuam, inclusive de trabalho escravo.

De acordo com a Comissão Pastoral da Terra (CPT) e o Ministério do Trabalho e Emprego (MTE), entre 2003 e 2010 foram resgatados mais de 10 mil trabalhadores em condições análogas à de escravo nos canaviais brasileiros (Repórter Brasil, 2011:5). A degradação nas relações de trabalho do setor canavieiro pode ser avaliada na seguinte tabela:

Tabela 1: Número de trabalhadores em situação análoga à escravidão

\begin{tabular}{|c|c|c|c|}
\hline \multirow{3}{*}{$\begin{array}{l}\text { Ano } \\
2007\end{array}$} & \multicolumn{3}{|c|}{ Atividades com mais trabalhadores resgatados (total e \%) } \\
\hline & Primeiro Lugar & Segundo Lugar & Terceiro Lugar \\
\hline & Cana $(3.060 /$ & / $24 \%) \quad$ Pecuária $(1.430$ & $\begin{array}{r}\text { Outro } \& \text { N.I. } \\
(538 / 9 \%)\end{array}$ \\
\hline 2008 & $48 \%) \quad$ Cana $(2.553 \quad /$ & Pecuária (1.029 & $\begin{array}{l}\text { Outras lavouras } \\
(731 / 14 \%)\end{array}$ \\
\hline 2009 & $45 \%) \quad$ Cana $(1.911 /$ & $\begin{array}{l}\text { Outras lavouras } \\
(804 / 19 \%)\end{array}$ & Pecuária (603 / \\
\hline 2010 & $\begin{array}{c}\text { Outras } \\
\text { lavouras }(1.014 / 33 \%\end{array}$ & Pecuária (784 / & Cana (535 / \\
\hline $2003-2006$ & $\begin{array}{l}\text { Pecuária } \\
(10.357 / 30 \%)\end{array}$ & $\begin{array}{l}\text { Outras lavouras } \\
(3.415 / 21 \%)\end{array}$ & Cana (1.605 / \\
\hline $2003-2010$ & /40\%) Pecuária (6.510 & Cana (10.010 / & $\begin{array}{l}\text { Outras lavouras } \\
(6.359 / 18 \%)\end{array}$ \\
\hline
\end{tabular}

Fonte: Repórter Brasil (2011:5).

De 2003 a 2006, o setor havia apresentado10\% dos casos de trabalho escravo (1.605). Em 2007, 2008 e 2009, as usinas de cana lideraram as estatísticas de escravos libertados. Em 2007, 51\% das pessoas resgatadas (3.060) trabalhavam no setor canavieiro; em 2008 esse número representou 48\% (2.553); e em 2009, 45\% (1.911). Em 2010, o setor foi palco da libertação de 535 trabalhadores (18\% do total).

\section{Conclusão}


Este estudo nos permitiu avaliar as tendências mais recentes no setor canavieiro e analisar o papel da produção de etanol no Brasil. Verificamos o crescente processo de formação de monopólios no setor, principalmente com participação de empresas petroleiras como Shell, BP (British Petroleum) e Petrobrás, que passaram a controlar uma parte significativa da produção de agrocombustíveis no país.

A maior concentração de capitais é acompanhada por um aumento da expansão territorial do monocultivo da cana, principalmente em áreas com acesso a infraestrutura, como a região Sudeste, e em regiões com vastas bacias hidrográficas, como o Cerrado. A tentativa do Brasil para manter o etanol competitivo no mercado internacional depende de diversas formas de apoio estatal, da superexploração do trabalho e da necessidade de expansão territorial, o que significa uma crescente apropriação de recursos naturais, como terra e água.

A pressão da bancada ruralista no Congresso Nacional para mudar o código florestal é parte deste contexto. Portanto, a tão propagada "eficiência" do setor não se sustenta, na medida em que se constata uma diminuição no ritmo de crescimento da produtividade, ao mesmo tempo em que crescem pressões do agronegócio para avançar sobre áreas de preservação ambiental. As formas de aquisição de terras para a expansão do monocultivo da cana ocorrem através do arrendamento ou fornecimento de médios e pequenos agricultores, que substituem a produção de alimentos (como verificamos no Sudeste, Centro-Oeste e Nordeste), além do avanço em terras públicas (como no Pontal do Paranapanema) e em áreas de preservação ambiental. ${ }^{22}$ Analisamos este processo no contexto da crise econômica internacional e do movimento de capitais financeiros que geram uma bolha especulativa, causando um forte aumento no preço da terra e dos alimentos.

O discurso sobre a "modernização" da produção de etanol serve para encobrir o aumento da exploração do trabalho. Como vimos, ao longo deste estudo, não é o

\footnotetext{
${ }^{22}$ Nossos estudos sobre as formas de aquisição de terras e sobre os impactos da expansão do monocultivo de cana no Brasil, entre 2004 e 2011, estão registrados nas seguintes publicações: http://www.social.org.br/revistacosanshel.pdf; http://www.social.org.br/revista-monopolio.pdf; http://www.social.org.br/cartilhaimpactoscana.pdf.
} 
"atraso" do setor que leva aos casos de descumprimento dos direitos trabalhistas. Pelo contrário, constatamos que a preponderante mecanização do corte da cana agrava a exploração dos trabalhadores. Altos investimentos de capital por meio de financiamento público, mecanização e intensificação da exploração do trabalho coexistem no setor sucroalcooleiro. É importante destacar o alto índice de endividamento e inadimplência da indústria canavieira, e a dependência de empréstimos a juros subsidiados que o BNDES tem fornecido ao setor. Ano após ano, as usinas demandam perdão e rolagem de dívidas com bancos estatais, além de diversas formas de subsídios e incentivos fiscais.

Estes fatos nos levam a concluir que o verdadeiro "produto" deste setor não é a cana, o açúcar ou o etanol, mas uma enorme dívida financeira, social e ambiental. Esta constatação nos ajuda a explicar a manutenção de mecanismos de superexploração do trabalho e de um modelo agrícola baseado no monocultivo e no latifúndio, que necessita expandir sua apropriação de bens naturais. Portanto, acreditamos que somente a transformação deste modelo por meio da crítica ao modo de produção capitalista como totalidade seria capaz de superar o estado de crises simultâneas no âmbito econômico, social e ambiental.

\section{Bibliografia}

ADORNO, Theodor. Dialética Negativa. Rio de Janeiro, Jorge Zahar Editora, 2009.

Agência Brasil, Estudo indica que desmatamento vai reduzir Cerrado à metade até 2050. Agência Brasil, 19 de junho de 2009. Disponível em: http://agenciabrasil.ebc.com.br. Acesso em 20 de março de 2011.

ALFREDO, Anselmo. Crítica à economia política do desenvolvimento e do espaço. Edição do autor, 2008 (mimeo).

. Crise Imanente, Abstração Espacial, Fetiche do Capital e Sociabilidade Crítica. Edição do autor, 2010 (mimeo).

BACCARIN, José Giacomo. A Constituição da Nova Regulamentação Sucroalcooleira. São Paulo, Editora Unesp, v. 5, n. 22, 2005.

A Desregulamentação e a Dupla Concentração Sucroalcooleira. Edição do autor, 2006. (Mimeo). 
. "Boletim - Ocupação formal no setor sucroalcooleiro em São Paulo. Jaboticabal, UNESP, 2009-2011, números 1-21. Disponível em: fcav.unesp.br/baccarin. Acesso em: 10 de agosto de 2011.

BELLUZZO, Luiz Gonzaga. Os antecedentes da tormenta. Campinas, Editora UNESP, 2009.

BRESSAN, Ângelo - Os Fundamentos da Crise do Setor Sucroalcooleiro no Brasil. Companhia Nacional de Abastecimento, 2010. Disponível em: http://www.conab.gov.br/conabweb/download/nupin/estudo_crise_cana.pdf.

Acesso em: 10/08/2011.

Folha de S. Paulo. "Tesouro paga Cr\$ 82,1 bilhões da dívida externa de 23 Usinas". Folha de São Paulo, 28 jan. 1991, Caderno Dinheiro. Disponível em: www.noticias.busca.uol.com.br. Acesso em: 02 jan. 2011.

- "Para EUA, visita de Bush intensifica "relação privilegiada" com Brasil". Folha de São Paulo, 13 fevereiro de 2007a. Caderno Dinheiro. Disponível em: www.noticias.busca.uol.com.br. Acesso em: 20 de abril de 2012.

"Presidente Lula chama usineiros de heróis". Folha de São Paulo, 20 de março de 2007b. Caderno Dinheiro. Disponível em: www.noticias.busca.uol.com.br. Acesso em: 20 de abril de 2012.

" "Usina pede recuperação judicial por causa da crise". Folha de São Paulo, 13 nov. 2008. Caderno Dinheiro. Disponível em: www.noticias.busca.uol.com.br. Acesso em: 20 de abril de 2012.

. "Usinas de álcool dão calote no físco em São Paulo". Folha de São Paulo, 07 jun. 2009. Caderno Dinheiro. Disponível em: www.noticias.busca.uol.com.br. Acesso em: 20 de abril de 2012.

"Setor sucroalcooleiro do Brasil tem pausa após grande expansão" Folha de São Paulo, 20 out. 2009. Caderno Dinheiro. Disponível em: www.noticias.busca.uol.com.br. Acesso em: 20 de abril de 2012.

GONÇALVES, Daniel Bertoli. Considerações sobre a expansão recente da lavoura canavieira no brasil. Informações Econômicas, São Paulo, Instituto de Economia Agrícola, v. 39, n. 10, out. 2009.

KURZ, Robert. A ascensão do dinheiro aos céus. Revista Krisis, n. 16-17, 1995. Disponível em: http://obeco.planetaclix.pt/rkurz101.htm. Acesso em: maio 2011.

O colapso da modernização: da derrocada do socialismo de caserna à crise da economia mundial. 5. ed. São Paulo, Paz e Terra, 1999.

LEFEBVRE, Henri. O fim da História. Lisboa, Publicações Dom Quixote, 1971. . A produção do espaço. Tradução de Sérgio Martins. Edição do tradutor, 1974 (mimeo). 
MARX, Karl. O Capital - Crítica da Economia Política. 5 Volumes. São Paulo, Abril Cultural, 1983.

MENDONÇA, Maria Luisa; PITTA, Fábio T.; XAVIER, Carlos Vinicius. Monopólio na Produção de Etanol no Brasil: A fusão Cosan-Shell. São Paulo, Rede Social de Justiça e Direitos Humanos, 2011. Disponível em: http://www.social.org.br. Acesso em 7 set. 2011.

MILANEZ, Artur, BARROS, N. R. \& FAVARET, P. "O perfil do apoio do BNDES ao setor sucroalcooleiro”. Em: BNDES Setorial, no 28, Rio de Janeiro, p. 3-36, setembro de 2008.

NOVAIS, Pedro (deputado relator). "Relatório Final da Comissão Parlamentar de Inquérito (CPI) destinada a investigar a dívida pública da União, Estados e Municípios, o pagamento de juros da mesma, os beneficiários destes pagamentos e o seu impacto nas políticas sociais e no desenvolvimento sustentável do País". Câmara dos Deputados, Brasília, maio de 2010.

POSTONE, Moishe. Time, Labor and Social Domination: a Reinterpretation on Marx Critical Theory. Cambridge University Press, 1993.

OGATA, Leandro Marcel. O setor sucroalcooleiro no Brasil: desenvolvimento, modernização e competitividade. Trabalho de Conclusão de Curso, FEA-USP, 2009 (Mimeo).

PITTA, Fábio T. - Modernização Retardatária e agroindústria sucroalcooleira paulista: o Proálcool como reprodução fíctícia do capital em crise. Dissertação de Mestrado em Geografia Humana, FFLCH-USP, São Paulo, 2011.

RAMOS, Pedro - "O Uso de mão-de-obra na lavoura canavieira: da legislação (agrária) do Estado Novo ao trabalho superexplorado na atualidade". Anais II Seminário de História do Açúcar: Trabalho População e Cotidiano. Itu, 11-15 novembro de 2007. São Paulo, Editora do Museu Paulista da USP, 2007.

. O trabalho na lavoura canavieira paulista: evolução recente, situação atual e perspectivas. Emprego e trabalho na Agricultura Brasileira. Buainain, A. M. e Dedecca, C. (coords.), Série Desenvolvimento Rural Sustentável, v. 9, p. 304-325. Brasília, IICA, 2008.

Financiamentos subsidiados e dividas de usineiros no Brasil: uma história secular e ... atual. Edição do autor, 2011 (mimeo).

REDE SOCIAL DE JUSTIÇA E DIREITOS HUMANOS. Direitos Humanos no Brasil 2009. São Paulo, 2009.

Rede Social de Justiça e Direitos Humanos e Comissão Pastoral da Terra, Os Impactos da Produção de Cana no Cerrado e Amazônia, 2008. Disponível em:

http://www.social.org.br/cartilhaimpactoscana.pdf. Acesso em: 22 de junho de 2012. 
Rede Social de Justiça e Direitos Humanos e Comissão Pastoral da Terra, Monopólio da Terra no Brasil: Impactos da expansão de monocultivos para a produção de agrocombustíveis, 2010. Disponível em: http://www.social.org.br/revistamonopolio.pdf. Acesso em: 28 de junho de 2012.

Repórter Brasil. O Etanol Brasileiro no Mundo - Os impactos Sócio-Ambientais Causados por Usinas Exportadoras. Repórter Brasil, maio de 2011. Disponível em: http://www.reporterbrasil.org.br/documentos/Canafinal_2011.pdf. Acesso em: 20 de abril de 2012.

Secretaria-Geral da Presidência da República. "Compromisso Nacional para Aperfeiçoar as Condições de Trabalho na Cana-de-Açúcar”. Secretaria-Geral da Presidência da República, Brasília, junho de 2009. Disponível em: http://www.secretariageral.gov.br/.arquivos/publicacaocanadeacucar.pdf. Acesso em 20 de abril de 2012.

SILVA, Maria Aparecida Moraes. Trabalho e trabalhadores na região do 'mar de cana e rio de álcool. Migrantes. São Carlos, EDUFSCAR, 2008.

Errantes do fim do século. São Paulo, Editora UNESP, 1999.

SILVA, Anderson; CARVALHO, Lena; MEDEIROS Otavio (organizadores). Dívida Pública: a experiência brasileira. Brasília: Secretaria do Tesouro Nacional, 2009.

TRIBUNAL DE CONTAS DA UNIÃO (TCU). Proálcool: Relatório de Auditoria Operacional. Brasília: TCU, 1990.

The Times. Shell deal promises river of green fuel in Brazil. The Times, 2 de fevereiro de 2010. Disponível em: http://business.timesonline.co.uk/tol/business/industry_sectors/natural_resources /article7011649.ece. Acesso em: 20 de abril de 2012.

THOMAZ JR., Antonio. Por trás dos canaviais: os nós da cana. São Paulo, Annablume/FAPESP, 2002.

Dinâmica Geográfica do Trabalho no Século XXI: (Limites Explicativos, Autocrítica e Desafios Teóricos). Presidente Prudente - Faculdade de Ciências e Tecnologia - Tese (livre-docência) -, 2009.

Universo On-Line (UOL) - Em Guarulhos, Lula e Bush anunciam parceria e enaltecem etanol. UOL, 9 de março de 2007. Disponível em:

http://noticias.uol.com.br/ultnot/2007/03/09/ult23u300.jhtm. Acesso em: 20 de abril de 2012. 